\title{
Molecular and biological functions of resveratrol in psychiatric disorders: a review of recent evidence
}

\author{
Mehran Shayganfard*
}

\begin{abstract}
Mental disorders including depression, anxiety, schizophrenia, autism spectrum disorders, bipolar and etc. have a considerable proportion of global disorder burden. Many nutritional psychiatry investigations have been conducted to evaluate the relationship between several individual nutrients such as herbal compounds with mental health. Resveratrol, a famous polyphenol compound, is known as an antioxidant, anti-inflammatory, anti-apoptotic, and neuroprotective agent regulating the function of brain and improves the behavioral factors associated with learning, anxiety, depression, and memory. In addition, this natural compound can cross the blood-brain barrier representing neurological influences. The pharmacological interest of utilizing resveratrol in mental disorders is due to its antiinflammatory and antioxidant features. The aim of this paper was to review the studies evaluated the potential effects of resveratrol on mental disorders.
\end{abstract}

Keywords: Resveratrol, Anxiety, Depression, Schizophrenia

\section{Introduction}

Mental disorders including depression, anxiety, schizophrenia, autism spectrum disorders (ASD), bipolar and etc. have a considerable proportion of global disorder burden [1]. Alterations and shifting of life styles from traditional features by globalization and urbanization are related to an elevation in mental disorders [2]. In recent decades, diet has been indicated to play an important role in both physical and mental disorders incidence and treatment [3]. Several associated processes showing the relationship between diet and mental disorders have been found in emerging evidence [4]. Many nutritional psychiatry investigations have been conducted to evaluate the relationship between several individual nutrients such as vitamins, minerals, omega-3, and herbal compounds with mental health [5].

*Correspondence: mshayganfard@yahoo.com

Department of Psychiatry, Arak University of Medical Sciences, Arak, Iran
Resveratrol (3,4',5-trihydroxystilbene; $\quad$ C14H12O3; MW $228.247 \mathrm{~g} / \mathrm{mol}$ ) is a polyphenolic compound existing in berries, grapes, peanuts, and wine. Resveratrol is known as an antioxidant, anti-inflammatory, anti-apoptotic, and anti-tumor agent [6-8]. Moreover, this natural compound has been reported as a neuroprotective agent. Additionally, evidence has been indicated that resveratrol is able protect both neuronal and glial cells from damages [9]. Interestingly, resveratrol regulates the function of brain and improves the behavioral factors associated with learning, anxiety, depression, and memory $[10,11]$. Resveratrol has a fast metabolism forming glucuronide and sulfate derivatives excreted through urine. Resveratrol can be detected in the blood at the concentrations range of nanomolar [12]. Recent research reported that the highest blood and brain levels of resveratrol can be detected about 20-30 min after oral administration maintaining up to $60 \mathrm{~min}$ [13]. Thus, resveratrol can cross the blood-brain barrier representing neurological influences. The pharmacological interest of utilizing resveratrol in mental disorders is due to its anti-inflammatory

c) The Author(s) 2020. This article is licensed under a Creative Commons Attribution 4.0 International License, which permits use, sharing, adaptation, distribution and reproduction in any medium or format, as long as you give appropriate credit to the original author(s) and the source, provide a link to the Creative Commons licence, and indicate if changes were made. The images or other third party material in this article are included in the article's Creative Commons licence, unless indicated otherwise in a credit line to the material. If material is not included in the article's Creative Commons licence and your intended use is not permitted by statutory regulation or exceeds the permitted use, you will need to obtain permission directly from the copyright holder. To view a copy of this licence, visit http://creativecommons.org/licenses/by/4.0/. The Creative Commons Public Domain Dedication waiver (http://creativecommons.org/publicdomain/zero/1.0/) applies to the data made available in this article, unless otherwise stated in a credit line to the data. 
feature in addition of its potential effects on these diseases [14]. Therefore, the combined effects represented by resveratrol have taken the attention of researchers investigating the novel drugs for treatment of mental disorders. The aim of this paper was to review the studies evaluated the potential effects of resveratrol on mental disorders.

\section{Neuroprotective features of resveratrol}

Resveratrol has low bioavailability due to an extensive intestinal and hepatic metabolism of its oral administration [15]. Considerably, numerous studies have indicated that resveratrol can cross the blood brain barrier. For instance, a recent study reported the levels of resveratrol in the brain, $4 \mathrm{~h}$ after intraperitoneal injection [16]. In another investigation, chronic intake of resveratrol was found to protect hippocampus of rodents from kainic acid [17]. The effect of oral administration of resveratrol on cognitive performance in either healthy people or patients with cognitive disorders have been investigated in limited literature. An investigation assessed vasodilatory function of resveratrol on blood flow improvement to promote cognitive action. The authors found that oral intake of resveratrol led to dose-dependent elevations in cerebral blood flow during cognitive function activating the frontal cortex [18]. Another study showed that resveratrol was able to increase endothelium dependent vasodilation and flow-mediated dilation of brachial artery enhancing cerebrovascular and cognitive performance [19].

Excessive amounts of reactive oxygen species (ROS) were reported to be related to cognitive deficits [20]. The antioxidant function of resveratrol has been proved in numerous studies due to its scavenging activity of free radicals as well as upregulating effects on antioxidant enzymes such as glutathione peroxidase [21, 22]. In addition, resveratrol is able to protect hippocampal neurons exposed to nitric oxide [23]. Interestingly, resveratrol play role in the cellular response by regulating the enzymes acting in stress response such as quinone reductase2 [24]. Quinone reductase2 has been shown to be upregulated in the hippocampus involved in learning and memory proposing that the elevated levels of this enzyme may enhance memory impairments [25]. Recent evidence showed that resveratrol suppressed quinone reductase 2 leading to elevation of cellular resistance against neural death mediated by oxidative stress [26]. Moreover, resveratrol is able to induce heme oxygenase 1 enhancing resistance against oxidative stress and neural damage [27]. Furthermore, resveratrol activates AMP-activated protein kinase (AMPK) regulating cell survival in oxidative stress response [28]. Additionally, resveratrol is able to protect mitochondria from oxidative stress [29].
Besides, microglial activation enhances neural death followed by brain damage by producing neurotoxic proinflammatory factors [30]. Resveratrol has been detected to reduce the pro-inflammatory factors such as cyclooxigenase1 (COX1) involved in cytokines production [22]. Pro-inflammatory production can be decreased by resveratrol via inhibiting nuclear factor kappaB (NF-kB) and activator protein- (AP-1) [31]. Moreover, resveratrol can reduce prostaglandins, $\mathrm{NO}$, and tumor necrosis factor- $\alpha$ $(\mathrm{TNF}-\alpha)$ [32-34].

\section{The pathogenesis of mental disorders Depression}

Major depression is known as one of the public health problems and a common psychiatric disease. It has been estimated to have 121 affected people entire the world [35]. Additionally, severe depression leads to a high morbidity and economic as well as social consequences [36]. Cognitive impairments as well as neurocognitive deficits of processing speed, learning, memory, executive performance, and attention are presented in patients suffering from depression $[37,38]$. The exact mechanisms of pathogenesis of this disorder are not clear yet, however some factors are shown to be associated with depression progression including genetic factors and non-genetic factors [39]. Non-genetic factors such as stress, emotional trauma, viral infection and neuro-related abnormalities may be complicated in the pathogenesis of depression [36]. An impairment in monoamine neurotransmitter system such as decreasing of serotonin, dopamine, and noradrenaline as well as neural damage and neural cell loss also have been reported to take role in the pathogenesis of depression [40, 41]. Several studies proposed that mitochondrial dysfunction leads to cellular damage in depression [42, 43]. Besides, it has been indicated that mitochondrial alterations may produce less ATP, reduced activities of enzymes involved in respiratory chain, and decreased physiological respiratory rate as well as capacity of electron transport chain in patients with depression $[44,45]$.

A large amounts of studies found the role of oxidative stress in the pathogenesis of depression [46]. In a recent investigation, increased concentrations of malondialdehyde (MDA), and therefore lipid peroxidation were reported in depressive patients [47, 48]. Similarly, another study found increased lipid peroxidation represented by elevated levels of $F(2)$-isoprostanes in patients suffering from depression $[49,50]$. 8-Hydroxydeoxyguanosine (8-OHdG) which is an indicator for oxidative stress to DNA, was elevated in depressive people [51]. In addition, various clinical trials and in vivo studies observed that SOD activity elevated in depression [52]. Furthermore, antioxidant molecules such as vitamin $\mathrm{E}$ and vitamin $\mathrm{C}$ 
were shown to be decreased in depressive individuals in comparison to healthy people $[53,54]$. Besides, the severity of depression disorder has a positive relationship with the levels of oxidative stress markers [55]. Elevated blood concentrations and gene expressions of pro-inflammatory cytokines including interleukin (IL)-1, IL-6, IL-8, interferon- $\gamma$ (IFN- $\gamma$ ) and tumor necrosis factor- $\alpha$ (TNF$\alpha)$ were demonstrated to be associated with depression $[56,57]$.

\section{ASD}

ASD are heterogeneous diseases characterized by restrictive behavior as well as communication and social interaction impairments [58]. Currently, the exact pathogenesis of ASD is not fully understood. Several abnormalities related and non-related to the central nervous system (CNS) have been proposed to be complicated in ASD pathogenesis leading to various cognitive and behavioral impairments [59-61]. ASD has been assumed to result from a group of systemic dysfunctions more than a specific organ abnormality [62]. In recent decades, researchers attempted to find genetic factors such as chromosomal abnormalities or a single gene related to ASD incidence but no exact relationship has been found yet [63]. Besides, recent investigations have been aimed to find gene-environment interaction, epigenetic factors, and pathophysiological process to explain the etiology and development of ASD. Currently, multiple factors including inflammation, oxidative stress, immune dysfunction, mitochondrial dysfunction, and environmental toxicities have been reported to be involved in psychiatric disorders like ASD [64, 65]. Neuro-inflammation characterized by CNS-specific and chronic glial reactions has been identified to take role in ASD pathogenesis. Neuro-inflammation leads to neuron growth abnormality, increased production of pro-inflammatory cytokines, and plaque generation and therefor damages brain tissue [66]. Environmental toxicants such as pesticides, heavy metals, and chemicals can affect biochemical mechanisms leading to increased oxidative stress, decreased glutathione and dysregulated cellular signaling pathways all of which can impair cell functions [67]. Another factor known to be involved in ASD pathogenesis is oxidative stress characterized by ROS-related cell damage [61]. Moreover, mitochondrial dysfunction is also complicated in many psychiatric disorders such as schizophrenia, bipolar, depression, dementia, and ASD [68, 69]. Mitochondrial dysfunction affect not only cell energy production but also other mitochondria-dependent processes such as programmed cell death or apoptosis, synaptic plasticity, calcium homeostasis, and neurotransmitter release $[70,71]$.

\section{Schizophrenia}

About 1 per cent of people suffer from schizophrenia, a chronic psychiatric disease, entire the world. This disorder initiates in early adulthood or late adolescence with psychotic symptoms containing positive, negative and cognitive symptoms [72]. Positive symptoms are those which are not represent in healthy people but are developed in individuals suffering from schizophrenia. These symptoms include paranoia, delusions, major thought disorder, visual and auditory hallucinations. Negative symptoms present in normal people but are decreased or disappeared in patients with schizophrenia including apathy, alogia, social withdrawal, anhedonia, and behavioral perseveration. Memory impairment, unstable attention, and executive activities disturbances are known as cognitive symptoms of schizophrenia. Recently, various neuro-immune factors have been detected to be complicated in the etiology and onset of neuropsychiatric diseases especially those developed during early brain formation such as schizophrenia [73]. Thus, immunological mechanisms targeting brain development are proposed to affect the brain and behavioral functions [74, 75]. Cytokines and their receptors have been observed to be highly expressed by neural and glial cells during the development of fetal brain suggesting to be effective on neurodevelopmental processes and neural survival [76]. Therefore, their abnormal amounts early brain development may affect neurodevelopmental mechanisms negatively leading to increased risk of the incidence of disorders with developmental origins like schizophrenia. Many investigations showed that anti-inflammatory and immunosuppressive interventions could decreased inflammation in schizophrenia [77, 78]. For instance, IL-10 production was seen to be higher in schizophrenia patients [79]. In addition, IL-1 gene complex has been suggested to play role in schizophrenia progression [80]. Thus, immune dysfunction along with chronic inflammation have been suggested to be relevant with infection-associated pathogenic processes in schizophrenia. Inflammatory response against postnatal environmental factors such as stress or drug abuse may impair brain maturation enhancing the incidence and development of chronic schizophrenia [81, 82]. Thus, it has been suggested that anti-inflammatory drugs may be able to delay the onset and progression of schizophrenia especially in the primary phases of the disease [83].

\section{The therapeutic effects of resveratrol on mental disorders} resveratrol has attracted researchers' attention as a potential compound for treatment of several mental diseases. We summarized the therapeutic functions of resveratrol in several pathways complicated in mental 
disorders including depression, anxiety, ASD, and schizophrenia as mental disorders.

\section{Depression \\ The effects of resveratrol on oxidative stress, inflammation, and apoptosis}

Chronic stress is a routine feature of our life inducing depression-like behaviors via alterations of proteins and some pathways in the brain. Resveratrol was found to represent anti-depressant effects. Numerous evidence indicated the potential roles of oxidative stress, inflammation, and apoptosis in the pathogenesis of depression. In an in vivo study, depression like behaviors induced in rats by submitting to 8 weeks of chronic unpredictable mild stress (CUMS) leading to decreased expressions of $\beta$-catenin, Bcl-2, GSH, and total antioxidant (TAC) as well as increased expressions of glycogen synthase kinase-3 $\beta$ (GSK-3 $\beta$ ), nuclear factor-kappa B (NF$\mathrm{kB})$, TNF- $\alpha$, IL- $1 \beta$, and MDA levels in hippocampus. Considerably, resveratrol administration improved all of these effects by inhibiting the neuro-inflammation, apoptosis, and oxidative stress as well as increasing hippocampal brain-derived neurotrophic factor (BDNF) and $\beta$-catenin concentrations [84]. Another work examined the role of resveratrol in ameliorating of ovariectomyinduced anxiety and depression-like behaviors in female mice. Resveratrol was able to reduce the depression and anxiety of the mice by attenuating activation of microglia and the NF-kB and NLRP3 in the hippocampus by increasing Sirt1 levels. Thus, the authors concluded that resveratrol is able to ameliorate the psycho-behavioral alterations induced by estrogen deficiency through suppression of inflammatory mechanisms and to be effective in the alleviation of postmenopausal changes [85]. The effects of resveratrol on testicular dysfunction associated with CUMS-induced depressive-like behaviors was assessed in an in vivo study. CUMS-induced depression led to elevated serum levels of corticosterone, decreased serum and hippocampus levels of serotonin, and reduced hippocampal levels of BDNF. In addition, CUMS reduced testosterone concentrations, increased testicular expressions of NF-kB, TNF- $\alpha, \mathrm{IL}-1 \beta$ and Bax as well as increased the expression of Bcl-2. CUMS also increased the oxidative stress in testis. Resveratrol administration presented testicular protective effects by inhibiting oxidative stress, apoptosis and inflammation resulting in elevation of serum levels of testosterone and $\beta$-catenin [86]. Wang et al., [7] investigated the anti-depressant effects of resveratrol in rat models with chronic restraint stress (CRS)-induced depression-like behaviors. The findings indicated that resveratrol administration remarkably attenuated the CRS-induced depressant behaviors. Resveratrol increased BDNF levels, and Bcl-2 expression in hippocampus. Additionally, resveratrol decreased Bax mRNA expression.

Increasing evidence showed that energy deficiency could be involved in the development of depression. Mitochondrial damage is the main cause of energy deficiency which may result in abnormalities in synaptic neurotransmission and therefor depression. Resveratrol was detected to increase hippocampal ATP levels, mitochondrial DNA, the expressions of SIRT1 and peroxisome proliferator-activated receptor $\gamma$ coactivator (PGC) $1 \alpha$ as well as decrease $\mathrm{Na}^{+}-\mathrm{K}^{+}$-ATPase and pyruvate levels. Moreover, resveratrol elevated serotonin levels and decreased its transporter, SERT, in the hippocampus [87]. Chen et al., [88] examined the influence of resveratrol on lipopolysaccharide (LPS)-induced depression-like behavior mice. They showed that resveratrol improved LPS-induced depression as well as apoptosis mitochondrial oxidative stress in the hippocampus. The effect of resveratrol on neurogenesis related to depression was determined in an investigation. Resveratrol treatment enhanced neurogenesis, upregulated Sirt1, and inhibited NF-kB activation ameliorating depression-like behaviors [89]. Moreover, resveratrol was reported to be able to increase neurotransmitters dopamine and serotonin significantly in the prefrontal cortex and NPY expression in the brain suggesting to act as an antagonist for depression treatment [90].

\section{The effect of resveratrol on Wnt/ßcatenin pathway}

The phosphoinositide 3 kinase and protein kinase $B$ (PI3K/Akt) signaling pathway is a process regulating critical cellular pathways including inflammation, growth and survival. Akt phosphorylation leads to the phosphorylation of glycogen synthase kinase-3 $\beta$ (GSK3 $\beta$ ) inhibiting GSK3 $\beta$ activity and effecting on its substrates including Bax, NF- $\mathrm{kB}$, TNF- $\alpha$, IL- 6 , tau protein, and c-Jun transcript [91, 92]. Recent evidence has indicated that the activity of GSK3 $\beta$ maybe elevated in animals with chronic stress. Moreover, the suppression of GSK3 $\beta$ activity decreased chronic stress induced neuronal apoptosis [93]. In addition, GSK3 $\beta$ polymorphisms has been shown to be related to major depressive diseases [94]. Chronic stress also leads to an imbalance between Bax and $\mathrm{Bcl}-2$ protein expressions which are pro-apoptotic and anti-apoptotic parameters, respectively. GSK-3 $\beta$ regulates $\beta$-catenin phosphorylation and degradation inhibiting the canonical Wnt pathway activation [95]. Recent investigations reported that prevention of GSK-3 $\beta$ might ameliorate depression [96]. increased activity of GSK-3 $\beta$ was found in depressed suicide victims [97]. evidence suggests that resveratrol can ameliorate the decreased ratio of p-GSK-3 $\beta /$ GSK-3 $\beta$ [98]. 
According to evidence, subclinical hypothyroidism $(\mathrm{SCH})$ has a close relationship with depression-like behavior. The aim of a recent work was to determine the antidepressant effect of resveratrol on rat model with $\mathrm{SCH}$. Rats received intra-gastric injection of resveratrol. The results demonstrated that resveratrol administration decreased plasma levels of thyroid-stimulating hormone (TSH) as well as hypothalamic mRNA levels of thyrotropin-releasing hormone (TRH). In addition, resveratrol treatment led to reduction in plasma levels of corticosterone and hypothalamic corticotrophinreleasing hormone $(\mathrm{CRH})$ expression. Resveratrol also upregulated the protein levels and phosphorylation of GSK3 $\beta$ as well as cyclin D1 and c-myc. Moreover, this compound decreased phosphorylation of $\beta$-catenin in hippocampus. Thus, resveratrol presented antidepressant function through decreasing the hyperactivity of hypothalamic-pituitary-adrenal (HPA) axis and regulating the $\mathrm{Wnt} / \beta$-catenin pathway and hypothalamic-pituitary-thyroid (HPT) axis [99]. The potential effects of resveratrol on HPA axis were confirmed by another work in which resveratrol led to a reduction in plasma levels of corticosterone and CRH expression in hypothalamus. This work also found that resveratrol decreased plasma levels of IL-6, CRP, TNF- $\alpha$, BDNF, $\beta$ catenin phosphorylation whereas increased the phosphorylation of GSK-3 $\beta$ in hippocampus [100]. The findings of another study also showed that resveratrol could ameliorate depression by activation of the Akt/GSK3 $\beta$ pathway and regulation of pro-inflammatory cytokines and apoptosis [101]. Oxidative stress and neuro-inflammation also attenuated by resveratrol via NETRIN1-mediated extracellular signalregulated kinase/cAMP signaling pathway representing antidepressant effects [102]. These studies propose a role for GSK-3 $\beta$ in the antidepressant features of resveratrol.

These studies evaluated efficacy of resveratrol for treatment of depression were ummarized in Table 1.

The theraupetic targets of resveratrol in depression were shown in Fig. 1.

\section{Anxiety disorder \\ The effect of resveratrol on limbic \\ hypothalamous-pituitary-adrenal gland axis (L-HPA)}

The L-HPA axis is an important system increasing survival potential against psychological problems. Glucocorticoid hormones are the eventuall products of this axis acting on several systems such as the brain. Physical and psychological challenges can activate the HPA axis reflexively leading to production of corticotrophin releasing hormone (CRH), ACTH hormone, and thereby glucocorticoid secretion [103]. Although their beneficial effects, the prolonged releasing of glucocorticoids may result in multiple metabolic and psychological problems
[104]. Evidence showed that hyperactivity of glucocorticoid negative feedback because of L_HPA dysregulation may be associated with some neuroendocrinological abnormalities [105]. On the other hand, the rapid elevation of brain-derivative neurotrophin factor (BDNF) expression precedes the activation of $\mathrm{CRH}$ in response to stress [106]. Moreover, BDNF is potentially involved in the regulation of HPA axis activity [107]. The L-HPA axis is reported as on of the main targets of resveratrol in anxiety disorder. For instance, the influence of transresveratrol on fear memory impairment and anxiety-like behaviors evaluated in a time-dependent sensitization (TDS) procedure-induced post-traumatic stress disorder (PTSD) model of mice. Trans-resveratrol alleviated abnormalities of L-HPA axis as well as the expressions of adrenal gland, corticotrophin-releasing factor levels, and glucocorticoid receptor in the hypothalamus, hippocampus, and amygdala. Moreover, trans-resveratrol elevated phosphorylation of cAMP response element binding protein (pCREB) and BDNF concentrations [108]. Similarly, another work detected the effect of trans-resveratrol on anxiety-like behavior and neuropathic pain in PTSD in vivo model induced by single-prolonged stress. Trans-resveratrol treatment led to decreased cold and mechanical allodynia, abnormalities of limbic hypothalamus-pituitary-adrenal axis. Furthermore, trans-resveratrol elevated protein kinase A, phosphorylated CREB protein, and BDNF [109].

\section{The effect of resveratrol on inflammation and sirtuin regulation}

Several studies claimed that inflammation can induce the progression of anxiety and depression $[110,111]$. In addition the increased levels of inflammatory cytokines in the brain has been reported in mice models of anxiety [112]. One of the main factors promoting inflammation and proinflammatory cytokines expression is nuclear factor kappa B (NF-kB). Multiple studies indicated that resveratrol treatment could alleviate anxiety- and depressionlike behaviors by inhibiting the NF-kB activation in the hippocampus [89].

In recent decades the epigenetic mechanisms have been suggested to be involved in the etiology of mood disorders such as anxiety, depression and related diseases [113-115]. Various epigenetic regulators induc epigenetic mechanisms leading to alteration in gene function. Sirtuins are the examples of these regulators known as class III HDACs [116]. Resveratrol is known as a potential sirtuin activator shown to be effective in recovery of hyper-anxiety in [117]. there are some evidence explore the effect of resveratrol on inflammation as well as sirtuin levels in anxiety. For instance, a recent study examined whether resveratrol ameliorates anxiety induced by 
Table 1 Animal studies that investigated the therapeutic effects of resveratrol on depression

\begin{tabular}{|c|c|c|c|c|c|}
\hline Disease & Dose of resveratrol & Model & Findings & Publish year & Refs. \\
\hline $\begin{array}{l}\text { Chronic unpredictable mild stress-induced } \\
\text { depression }\end{array}$ & $80 \mathrm{mg} / \mathrm{kg}$ & In vivo & $\begin{array}{l}\text { Inhibited neuro-inflammation, oxidative } \\
\text { stress, and apoptosis, increased hip- } \\
\text { pocampal BDNF and } \beta \text {-catenin levels }\end{array}$ & 2018 & {$[84]$} \\
\hline Ovariectomy-induced depression & $20 \mathrm{mg} / \mathrm{kg}$ & In vivo & $\begin{array}{l}\text { Decreased activation of microglia, NF-kB, } \\
\text { and NLRP3 in hippocampus, increased } \\
\text { levels of Sirt1 }\end{array}$ & 2019 & {$[85]$} \\
\hline $\begin{array}{l}\text { Chronic unpredictable mild stress-induced } \\
\text { depression }\end{array}$ & $80 \mathrm{mg} / \mathrm{kg}$ & In vivo & $\begin{array}{l}\text { Inhibited oxidative stress, apoptosis and } \\
\text { inflammation elevation of serum levels of } \\
\text { testosterone and } \beta \text {-catenin }\end{array}$ & 2019 & {$[86]$} \\
\hline Chronic restraint stress- induced depression & $80 \mathrm{mg} / \mathrm{kg}$ & In vivo & $\begin{array}{l}\text { Increased BDNF levels, and Bcl-2 expression } \\
\text { in hippocampus, decreased Bax mRNA } \\
\text { expression }\end{array}$ & 2016 & {$[7]$} \\
\hline Subclinical hypothyroidism & $15 \mathrm{mg} / \mathrm{kg}$ & In vivo & $\begin{array}{l}\text { Decreased TSH, TRH, corticoesterone, } \\
\text { and CRH hormones, increased GSK3 } \beta \\
\text { phosphorylation, cyclin D1 and c-myc, } \\
\text { decreased } \beta \text {-catenin phosphorylation, } \\
\text { decreased activity of HPA axis }\end{array}$ & 2016 & {$[99]$} \\
\hline $\begin{array}{l}\text { Chronic unpredictable mild stress-induced } \\
\text { depression }\end{array}$ & 15 mg/kg/day & In vivo & $\begin{array}{l}\text { Decreased corticosterone and CRH, } \\
\text { increased IL-6, CRP, TNF-a, BDNF, } \beta \text { catenin } \\
\text { phosphorylation, decreased the phos- } \\
\text { phorylation of GSK-3 } \beta \text { in hippocampus }\end{array}$ & 2017 & {$[100]$} \\
\hline $\begin{array}{l}\text { Chronic unpredictable mild stress-induced } \\
\text { depression }\end{array}$ & 40 or 80 mg/kg/day & In vivo & $\begin{array}{l}\text { activated Akt/GSK3 } \beta \text { pathway and regu- } \\
\text { lated pro-inflammatory cytokines and } \\
\text { apoptosis }\end{array}$ & 2019 & {$[101]$} \\
\hline Ouabain-induced depression & $10 \mathrm{mg} / \mathrm{kg}$ & In vitro/in vivo & $\begin{array}{l}\text { Decreased oxidative stress and neuro- } \\
\text { inflammation }\end{array}$ & 2018 & {$[102]$} \\
\hline $\begin{array}{l}\text { Chronic unpredictable mild stress-induced } \\
\text { depression }\end{array}$ & $50 \mathrm{mg} / \mathrm{kg}$ & In vivo & $\begin{array}{l}\text { Increased hippocampal ATP levels, mito- } \\
\text { chondrial DNA, the expressions of SIRT1 } \\
\text { and PGC1a, decreased } \mathrm{Na}^{+}-\mathrm{K}^{+} \text {-ATPase } \\
\text { and pyruvate levels, increased serotonin } \\
\text { levels, decreased SERT in the hippocam- } \\
\text { pus }\end{array}$ & 2020 & {$[87]$} \\
\hline LPS-induced depression & $0.3 \mathrm{mg} / \mathrm{kg}$ & In vivo & $\begin{array}{l}\text { Improved apoptosis and oxidative stress } \\
\text { in hippocampus and depressant-like } \\
\text { behaviors }\end{array}$ & 2017 & {$[88]$} \\
\hline LPS-induced depression & $20 \mathrm{mg} / \mathrm{kg}$ & In vivo & $\begin{array}{l}\text { Enhanced neurogenesis, upregulated Sirt1, } \\
\text { and inhibited NF-kB activation }\end{array}$ & 2016 & [89] \\
\hline $\begin{array}{l}\text { Chronic unpredictable mild stress-induced } \\
\text { depression }\end{array}$ & 10,20 and $30 \mathrm{mg} / \mathrm{kg}$ & In vivo & $\begin{array}{l}\text { Increased dopamine and serotonin in the } \\
\text { prefrontal cortex and increased NPY } \\
\text { expression in the brain }\end{array}$ & 2019 & {$[90]$} \\
\hline
\end{tabular}

ovariectomy in mice via suppression of inflammation. The authors reported that anxiety-like behaviors were significantly diminished by resveratrol administration. Additionally, resveratrol was able to decrease the activation of microglia in the hippocampal dentate gyrus as well as hippocampal levels of NLRP3, and NF-kB increased by estrogen deficiency. Furthermore, resveratrol inhibited cytokine production by boosting Sirt1 concentrations counteracting estrogen deficiency and therefore, its psycho-behavioral consequences [85]. Epidemiological evidence revealed that depression, anxiety and associated mental disorders may incidence as diabetes comorbidities. In another study pre-diabetic rats with hyper-anxiety behavior were used to investigate the mechanisms of these comorbidities. Rats were administered with resveratrol and metformin along with fructose. Resveratrol represented more effectiveness both in metabolic and anxiety disorders than metformin. Moreover, resveratrol was showed to upregulate some nuclear sirtuins including Sirt1 and Sirt7 decreased in the striatum of pre-diabetic rats. Thus, it was concluded that resveratrol might alleviate pre-diabetes-related hyperanxiety via regulation of sirtuins [118].

Magaji et al., also found anxiolysis and anti-psychotic effects of 14-days treatment of resveratrol in mice model of anxiety and schizophrenia [119]. Pterostilbene is a natural analog of resveratrol with similar effects, however its neurological functions have not been fully explored. 


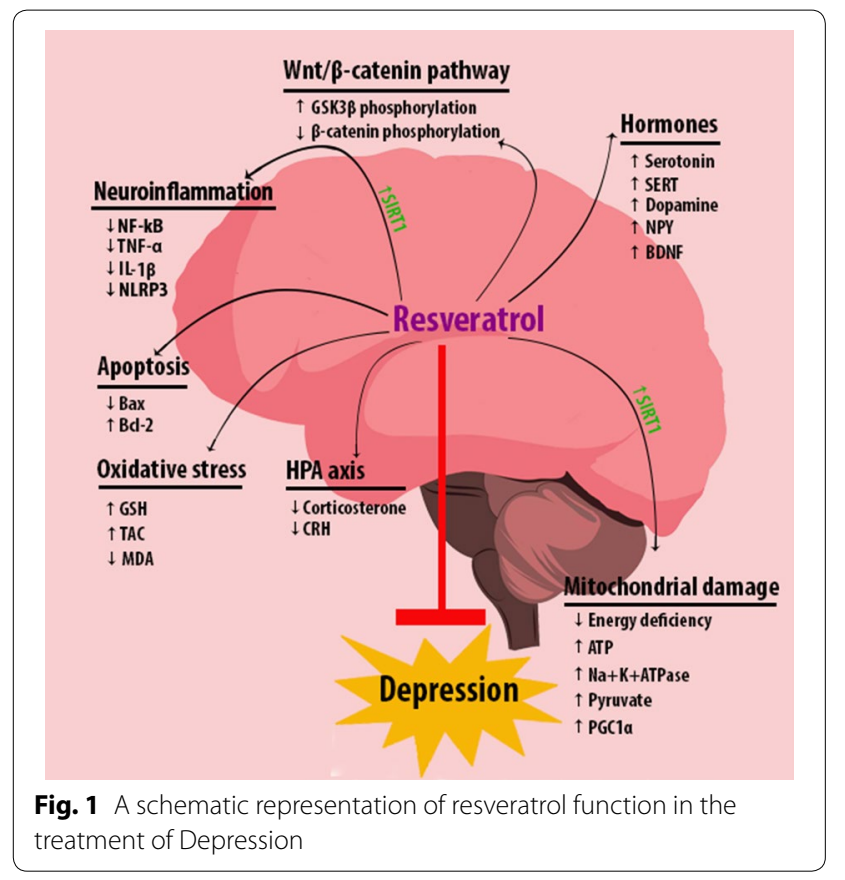

An investigation demonstrated that pterostilbene could represented anxiolytic function at 1 and $2 \mathrm{mg} / \mathrm{kg}$ doses, however this effect was not observed at higher doses. Thus, this was concluded that pterostilbene might be beneficial for the treatment of anxiety disorder as the same as resveratrol [120].

Table 2 indicates summarized data of studies evaluated role of resveratrol for treatment of anxiety.

The effects of resveratrole on pathways complicated in anxiety were indicated in Fig. 2.

\section{ASD}

ASD is related to neural and synaptic deficits. The pathophysiology of ASD has been shown to be associated with oxidative stress, immune dysfunction, and excitation-inhibition imbalance. ASD is characterized by impairments in repetitive and social interactions, communication, restricted and stereotyped-like behavior. Multiple study have been conducted to investigate the effect of resveratrol and its mechanisms of action on ASD. In an in vivo study rodent model of autism induced by prenatal exposure to valproic acid was used for evaluating the effects of resveratrol on social behaviors. This study showed that resveratrol alleviated impairment of social behavior [121]. In contrast, a clinical trial showed no significant influence of resveratrol on patients with ASD. Resveratrol at dose of $250 \mathrm{mg}$ twice per day was administered by the patients for 10 weeks. Irritability, lethargy/social withdrawal, stereotypic behavior, and inappropriate speech in resveratrol group were the same as the placebo group. Hyperactivity/non-compliance score was statistically decreased in the resveratrol group compared to the placebo group. Overall, this study found no considerable effect for resveratrol treatment on irritability of ASD patient while it could alleviate hyperactivity/non-compliance of ASD cases [122].

\section{The effect of resveratrol on oxidative stress and inflammation}

Chemokine receptors have been indicated to play important role in CNS involved in the progression of many neuro-inflammatory disorders. Interestingly, matrix metalloproteinases, pro-inflammatory cytokines, oxidative stress and mitochondrial dysfunction are the potential factors triggering neuro-inflammation resulting in neural dysfunction all of which are involved in ASD pathogenesis. Evidence supports the anti-inflammatory and andtioxidant effects of resveratrol in ASD. For example, the effect of resveratrol was assessed on neuroinflammatory model of rats with ASD. Resveratrol treatment led to a significant amelioration of behavioral, biochemical, molecular, sensory, and neurological deficits via

Table 2 Animal studies that investigated the therapeutic effects of resveratrol on anxiety

\begin{tabular}{|c|c|c|c|c|c|}
\hline Disease & Dose of resveratrol & Model & Findings & Publish year & Refs. \\
\hline PTSD-induced anxiety & 10,20 and $40 \mathrm{mg} / \mathrm{kg}$ & In vivo & $\begin{array}{l}\text { Alleviate L-HPA axis, corticotrophin-releasing factor levels, and } \\
\text { glucocorticoid receptor in the hypothalamus, hippocampus, } \\
\text { and amygdala, increased pCREB and BDNF }\end{array}$ & 2018 & {$[108]$} \\
\hline PTSD-induced anxiety & $40 \mathrm{mg} / \mathrm{kg}$ & In vivo & $\begin{array}{l}\text { Alleviate L-HPA axis, elevated protein kinase A, phosphorylated } \\
\text { CREB protein, and BDNF }\end{array}$ & 2020 & {$[109]$} \\
\hline Anxiety & 200 and $400 \mathrm{mg} / \mathrm{kg}$ & In vivo & Anxiolysis and anti-psychotic effects & 2017 & {$[119]$} \\
\hline Ovariectomy-induced anxiety & $20 \mathrm{mg} / \mathrm{kg}$ & In vivo & $\begin{array}{l}\text { Decreased anxiety-like behaviors, decreased activation of micro- } \\
\text { glia in the hippocampal dentate gyrus, hippocampal levels of } \\
\text { NLRP3, and NF-kB, inhibited cytokine production, increased } \\
\text { Sirt1 concentrations }\end{array}$ & 2019 & {$[85]$} \\
\hline Diabetes-induced anxiety & 10 mg/kg/day & In vivo & Increased Sirt1 and Sirt7 & 2016 & {$[118]$} \\
\hline Anxiety & 1 and $2 \mathrm{mg} / \mathrm{kg}$ & In vivo & Anxiolytic function & 2013 & [120] \\
\hline
\end{tabular}




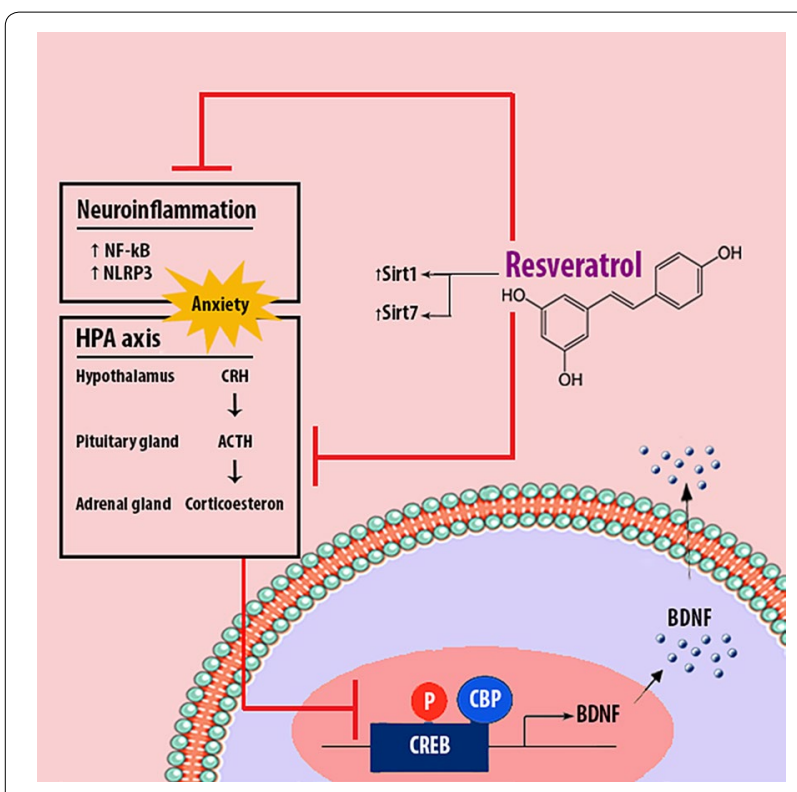

Fig. 2 A schematic representation of resveratrol function in the treatment of Anxiety

inhibiting oxidative stress, mitochondrial dysfunction, MMP-9 and TNF- $\alpha$ expression in a dose dependent manner [10]. Another work demonstrated that resveratrol upregulated the gene expressions of Sirt1 and early growth response factor 3 (Egr3) in mice with autism leading to amelioration of their social behavior [123]. Xie et al., [124] hypothesized that exposure to prenatal progestin may enhance ASD development ameliorating by resveratrol treatment. Prenatal exposure of progestin in pregnant mice reduced estrogen receptor $\beta$ (ER $\beta$ ) expression in the amygdala leading to autism-like behavior. Prenatal and postnatal treatment with resveratrol activated $E R \beta$ via histone and DNA demethylation on ER $\beta$ promoter as well as reduced oxidative stress, mitochondrial dysfunction, and lipid metabolism in the brain therefor, alleviated autism-like behavior.

\section{The effect of resveratrol on neuroimmune regulation}

Immune dysregulation has been found to take role in the development of ASD and multiple markers of system neuroinflammation have been reported in ASD [63].

The role of immune abnormalities in the develop-ment of autism is beginning to emerge. Immune abnormalities also found in children with ASD at a young age [125]. In addition, the gene expression and function of immune cells were recognized to be dysregulated in ASD [126]. Moreover, several chemokines and cytokines increased in children with ASD [127]. Dysregulation of T helper (Th1, Th2, and Th17) and T regulatory cells transcription factor signaling were also found in autistic children
(Ahmad et al. 2017b). Toll-like receptors (TLRs) are widely expressed in immune cells in the brain playing an essential role in neurophysiology [127]. Moreover, evidence showed the distribution of LTRs expression in the brain during neurocysticercosis [128]. Resveratrol is able to improve neuroimmune dysregulation by suppressing the inflammation-related signaling pathways. The $\mathrm{BTBR} \mathrm{T}^{+}$Itpr $^{\text {tf }} / \mathrm{J}$ (BTBR) autistic mouse model showing impaired juvenile play, social behavior, and low reciprocal social interaction was used for assessing resveratrol effects on autism treatment. The results indicated that $\mathrm{CD} 4^{+}$TLR2, CD $4^{+} \mathrm{TLR} 3, \mathrm{CD} 4^{+} \mathrm{TLR} 4, \mathrm{CD} 4^{+} \mathrm{NF}-\mathrm{kB}{ }^{+}$, and $\mathrm{CD}_{4}{ }^{+} \mathrm{iNOS}^{+}$levels were decreased in spleen cells followed by resveratrol treatment. In addition, the gene expressions and protein levels of TLR2, TLR3, TLR4, NF- $k B$, iNOS, and COX-2 were reduced in the brain tissue after resveratrol intervention [129]. Another study detected the role of resveratrol in improving of the dysregulation of transcription factor in two models of autistic mice including BTBR mice and C57BL/6 (B6) mice. In both types, resveratrol led to upregulation of Foxp $3^{+}$and reduction of T-bet ${ }^{+}$, GATA- $3^{+}$, and $\mathrm{IL}^{-17 \mathrm{~A}^{+}}$expression and protein levels in $\mathrm{CD} 4^{+}$cells, spleen, and brain tissues in comparison to control groups [130]. Prenatal exposure to valproic acid may lead to ASD incidence. Pregnant rats were treated with resveratrol along with valproic acid. The results showed that resveratrol could prevent all mechanisms initiated by valproic acid suggesting to be a potential protective agent for ASD incidence [131]. Evidence indicated that JAK-STAT signaling pathway is related to some neurological diseases. A recent work showed that resveratrol was able to decrease IL- $6^{+}$, TNF$\alpha^{+}, \mathrm{IFN}^{-} \gamma^{+}$, and $\mathrm{STAT}^{+}{ }^{+}$in $\mathrm{CD} 4^{+}$spleen cells of autistic mice compared to control group. The result of this work also revealed that resveratrol administration reduced the genes expression and protein levels of TNF- $\alpha$, IL- 6 , IFN- $\gamma$, JAK1, and STAT3 in the brain tissue [132]. Previous research declaimed that exposure to maternal hormone may develop ASD. An investigation evaluated the influence of resveratrol on the $\mathrm{C}-\mathrm{C}$ chemokine receptor (CCR) and C-X-C motif chemokine receptor (CXCR) $\left(\mathrm{CCR}^{+}, \mathrm{CCR}^{+}, \mathrm{CCR}^{+}\right.$and $\mathrm{CCR}^{+}, \mathrm{CXCR}^{+}$and $\left.\mathrm{CXCR}^{+}\right)$in cluster of differentiation 4-positive $\left(\mathrm{CD} 4^{+}\right)$ $\mathrm{T}$ cells in the spleen and brain tissues of BTBR mice. Resveratrol treatment resulted in reduction of CCR and CXCR expression in $\mathrm{CD}^{+} \mathrm{T}$ cells in spleen and brain tissues in comparison with control group. Thus, resveratrol could decreased the chemokine receptors providing a unique goal for therapeutic strategies for autism [133].

This data of investigations assessing resveratrol effects for curing of ASD disorders summarized in Table 3.

The mechanisms of function of resveratrol in ASD were shown in Fig. 3. 
Table 3 Studies that investigated the therapeutic effects of resveratrol on ASD

\begin{tabular}{|c|c|c|c|c|c|}
\hline Disease & Dose of resveratrol & Model & Findings & Publish year & Ref \\
\hline \multicolumn{6}{|l|}{ Animal stusies } \\
\hline Valproic acid-induced ASD & $3.6 \mathrm{mg} / \mathrm{kg}$ & In vivo & Improved social behavior & 2014 & [121] \\
\hline $\begin{array}{l}\text { Oxytocin receptor gene knockout } \\
(\text { Oxtr-KO) and valproic acid- } \\
\text { induced ASD }\end{array}$ & $30 \mathrm{mg} / \mathrm{kg}$ & In vivo & Upregulated Sirt1 and Egr3, improved social behaviors & 2020 & [123] \\
\hline BTBR-induced ASD & 20 and $40 \mathrm{mg} / \mathrm{kg}$ & In vivo & $\begin{array}{l}\text { Decreased levels } \mathrm{CD} 4^{+} \mathrm{TLR}^{+}{ }^{+}, \mathrm{CD}^{+}{ }^{+} \mathrm{TLR}^{+}{ }^{+}, \mathrm{CD}^{+}{ }^{+} \mathrm{TLR}^{+}{ }^{+} \\
\mathrm{CD} 4^{+} \mathrm{NF}-\mathrm{KB}{ }^{+} \text {, and } \mathrm{CD} 4^{+} \mathrm{iNOS}^{+} \text {in spleen cells, } \\
\text { decreased TLR2, TLR3, TLR4, NF-KB, iNOS, and COX-2 } \\
\text { in the brain tissue }\end{array}$ & 2018 & [129] \\
\hline Valproic acid-induced ASD & $3.6 \mathrm{mg} / \mathrm{kg}$ & In vivo & Prevented ASD-like behaviors & 2018 & [131] \\
\hline B6- and BTBR-induced ASD & 20 and $40 \mathrm{mg} / \mathrm{kg}$ & In vivo & $\begin{array}{l}\text { upregulated Foxp } 3^{+} \text {, reduced T-bet }{ }^{+}, \mathrm{GATA} 3^{+} \text {, and } \\
\mathrm{IL}-17 \mathrm{~A}^{+} \text {expressions and protein levels in } \mathrm{CD}^{+} \text {cells, } \\
\text { spleen, and brain tissues }\end{array}$ & 2017 & [130] \\
\hline BTBR-induced ASD & 20 and 40 mg/kg & In vivo & $\begin{array}{l}\text { Decreased levels of IL- } 6^{+}, \mathrm{TNF}_{-} \mathrm{a}^{+} \text {, IFN- } \gamma^{+} \text {, and STAT3 }{ }^{+} \text {in } \\
\mathrm{CD}^{+} \text {spleen cells and brain tissue }\end{array}$ & 2017 & [132] \\
\hline Decreased ERß- induced ASD & $20 \mathrm{mg} / \mathrm{kg}$ & In vivo & $\begin{array}{l}\text { activated ERß, decreased oxidative stress, mitochondrial } \\
\text { dysfunction, and lipid metabolism in the brain }\end{array}$ & 2018 & [124] \\
\hline BTBR-induced ASD & 20 and $40 \mathrm{mg} / \mathrm{kg}$ & In vivo & $\begin{array}{l}\text { Decreased CCR and CXCR expression in } C D 4^{+} T \text { cells in } \\
\text { spleen and brain tissues }\end{array}$ & 2016 & [133] \\
\hline ASD & 5,10 and $15 \mathrm{mg} / \mathrm{kg}$ & In vivo & $\begin{array}{l}\text { Inhibited oxidative stress, mitochondrial dysfunction, } \\
\text { MMP-9 and TNF-a expression }\end{array}$ & 2017 & {$[10]$} \\
\hline \multicolumn{6}{|l|}{ Human studies } \\
\hline ASD & 250 mg twice per day & Human & Decreased hyperactivity/non-compliance score & 2020 & [122] \\
\hline
\end{tabular}

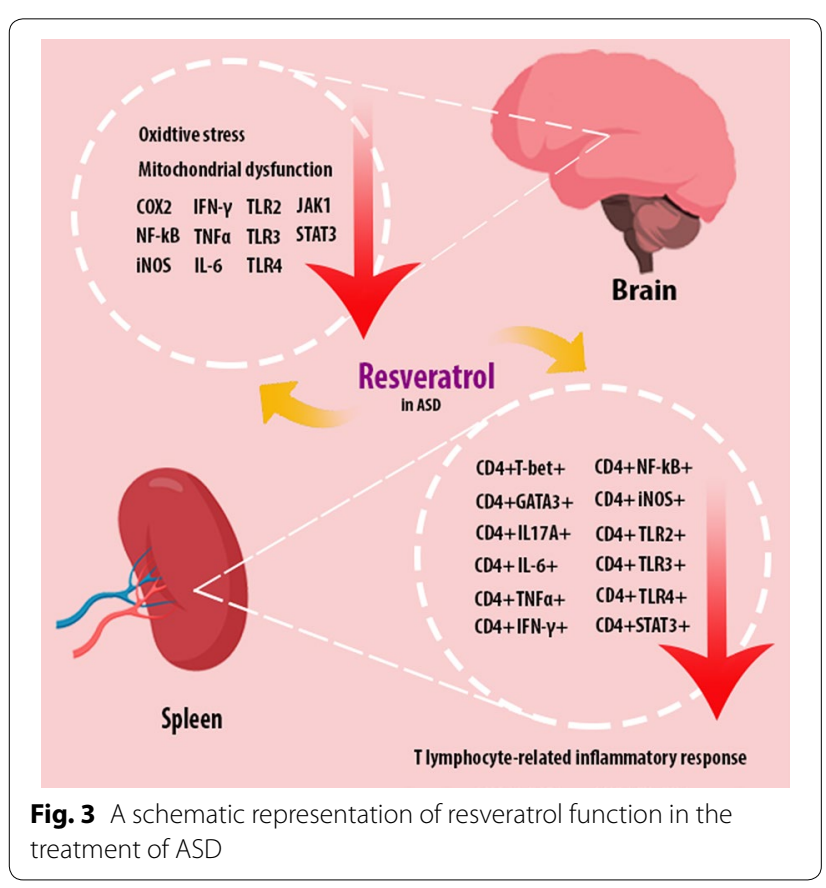

\section{Schizophrenia}

Schizophrenia is characterized by psychotic symptoms and cognitive impairments. Some studies revealed that resveratrol might be potential in treatment of schizophrenia due to its neuroprotective activities. Recently, an in vivo study was conducted to evaluate antipsychotic properties of resveratrol in schizophrenia. Schizophrenic mice were pretreated with resveratrol followed by behavioral tests on the 15th day. Anti-psychiotic and anxiolytic functions of resveratrol were determined by hole board and staircase tests as well as stereotypyinduced apormorphine and swim-induced groomin testes, respectively. The results indicated that resveratrol administration led to a significant reduction in the mean episodes of rearing as well as the mean climbing scores while it did not considerably decrease the mean number of head dips. Thus, it was concluded that resveratrol could represent anxiolytic and anti-psychotic influence in mice model [119]. Recent data reported that schizophrenia are commonly overweight or obese with many metabolic comorbidities. Moreover, these patients have a high mortality rate and life expectancy due to cardiovascular problems. In an in vivo research, resveratrol was administrated to neonatal rats with schizophrenia-like behavior in order to explore its effect on the alleviation of cognitive and motor deficits as well as associated molecular alterations. Findings showed that resveratrol contributed to the expressions of SIRT1 and BDNF as well as amelioration of oxidative stress [134].

Common antipsychotic drugs used for schizophrenia treatment may cause motor disorders such as tardive dyskinesia. In a recent study the influence of resveratrol administration on behavioral alterations result from 
Table 4 Studies that investigated the therapeutic effects of resveratrol on schizophrenia

\begin{tabular}{|c|c|c|c|c|c|}
\hline Disease & Dose of resveratrol & Model & Findings & Publish year & Ref \\
\hline \multicolumn{6}{|l|}{ Animal studies } \\
\hline Schizophrenia & 200 and $400 \mathrm{mg} / \mathrm{kg}$ & In vivo & $\begin{array}{l}\text { reduced mean episodes of rearing and mean climbing } \\
\text { scores }\end{array}$ & 2017 & [119] \\
\hline MK-801-induced schizophrenia & $40 \mathrm{mg} / \mathrm{kg}$ or $80 \mathrm{mg} / \mathrm{kg}$ & In vivo & $\begin{array}{l}\text { Increased expression of SIRT1 and BDNF, decreased oxida- } \\
\text { tive stress }\end{array}$ & 2020 & [134] \\
\hline Schizophrenia & $20 \mathrm{mg} / \mathrm{kg}$ & In vivo & Decreased VCMs & 2017 & [135] \\
\hline MIA-induced schizophrenia & $40 \mathrm{mg} / \mathrm{kg}$ & In vivo & Ameliorated hyperlocomotion and social behavior & 2020 & [136] \\
\hline \multicolumn{6}{|l|}{ Human studies } \\
\hline Schizophrenia & 200 mg/day & Human & No significant changes & 2016 & [137] \\
\hline Schizophrenia & 200 mg/day & Human & No significant changes & 2016 & [138] \\
\hline
\end{tabular}

chronic treatment with fluphenazine in rats was determined. The treatment of fluphenazine led to decreased body weight gain and the number of rearing and crossing while co-administration with resveratrol led to none of these changes. Fluphenzine also elevated the frequency and intensity of vacuous chewing movments (VCMs) whereas resveratrol cotreatment decreased the VCMs. Additionally, the number of VCMs was negatively correlated with monoamine oxidase- $\mathrm{B}(\mathrm{MAO}-\mathrm{B})$ in the stratum of rats [135]. It has been reported that the infection of several agents such as bacteria, arboviruses, or some protozoans during pregnancy may be related to increased risk of schizophrenia. Immunological mechanisms activated by infection may impair neural progenitor and CNS functions. In a study, pregnant mice induced by maternal immune activation (MIA) were treated with resveratrol. Behavioral tests were performed on the day 45 after birth. Results showed that resveratrol administration ameliorated the hyperlocomotion as well as social behavior. Resveratrol inhibited the influence of MIA on the expressions of Syn 1 and Olig1 in the cortex and hippocampus therefore impacting on synaptic and oligodendrogenesis mechanisms [136]. In a randomized, double-blind controlled trial, patients with schizophrenia enrolled to assess the effect of resveratrol on metabolic parameters including serum glucose and cardiovascular risk factors. In summary, resveratrol intake led to no significant changes. However, lipid profile exacerbated in placebo group. It was concluded that resveratrol administration might prevent lipid profile worsening [137]. In another randomized, double blind, and controlled trial patients suffering from schizophrenia were subjected to receive resveratrol supplementation or placebo for 1-month. Neuropsychology performance and psychology severity were evaluated. The results indicated that neuropsychology performance criteria including episodic and work memory, capacity of attention and concentration, interference measures, inhibitory control, mental flexibility, and selective attention as well as psychology severity did not improved after 1 month of resveratrol treatment [138]. Table 4 shows a summary of these studies.

\section{Conclusions}

In current article, we reviewed recent achievements of chitosan-based drug delivery systems for curing of the mental disorders including depression, anxiety, ASD, and schizophrenia. Mental disorders are multifactorial diseases requiring drugs that are able to effective on many brain targets. Resveratrol have been shown to have pleiotropic neuroprotective effects appear to be a potential candidate for using in treatment of mental disorders. Although, its clinical effectiveness and application are not clear yet. Resveratrol is able to interfere with multiple mechanisms complicated in the beginning stages of pathology of mental disorders preventing or slowing down them. However, the establishment of the effective dose, standardized preparations, and improvement of bioavailability are the primary points which should be considered. In recent decades, resveratrol has received great attentions for curing mental disorders due to its various therapeutic features such as antioxidant and antiinflammatory effects and many animal studies have been conducted in this way, however clinical investigations are limited. Thus, the potential features of resveratrol in mental disorders treatment should be examined in longterm interventions in clinical manner.

\section{Acknowledgements}

Not applicable.

\section{Authors' contributions}

MS contributed in conception, design and drafting of the manuscript. The author read and approved the final manuscript.

\section{Funding}

Not applicable.

Consent for publication

Not applicable. 


\section{Competing interests}

The authors declare no conflict of interest.

Received: 20 September 2020 Accepted: 29 October 2020

Published online: 07 November 2020

\section{References}

1. Whiteford HA, Degenhardt L, Rehm J, Baxter AJ, Ferrari AJ, Erskine HE, et al. Global burden of disease attributable to mental and substance use disorders: findings from the Global Burden of Disease Study 2010 Lancet (London, England). 2013;382:1575-86.

2. Logan AC, Jacka FN. Nutritional psychiatry research: an emerging discipline and its intersection with global urbanization, environmental challenges and the evolutionary mismatch. J Physiol Anthropol. 2014;33:22.

3. Jacka FN, Sacks G, Berk M, Allender S. Food policies for physical and mental health. BMC Psychiatry. 2014;14:132.

4. Jacka FN, Cherbuin N, Anstey KJ, Sachdev P, Butterworth P. Western diet is associated with a smaller hippocampus: a longitudinal investigation. BMC Med. 2015;13:215.

5. Dawson SL, Dash SR, Jacka FN. The importance of diet and gut health to the treatment and prevention of mental disorders. Int Rev Neurobiol. 2016:131:325-46.

6. de Oliveira MR, Nabavi SF, Manayi A, Daglia M, Hajheydari Z, Nabavi SM. Resveratrol and the mitochondria: from triggering the intrinsic apoptotic pathway to inducing mitochondrial biogenesis, a mechanistic view. Biochem Biophys Acta. 2016;1860:727-45.

7. Wang X, Xie Y, Zhang T, Bo S, Bai X, Liu H, et al. Resveratrol reverses chronic restraint stress-induced depression-like behaviour: involvement of BDNF level, ERK phosphorylation and expression of $\mathrm{BCl}-2$ and $\mathrm{Bax}$ in rats. Brain Res Bull. 2016;125:134-43.

8. Kalantari H, Das DK. Physiological effects of resveratrol. BioFactors (Oxford, England). 2010;36:401-6.

9. Albani D, Polito L, Signorini A, Forloni G. Neuroprotective properties of resveratrol in different neurodegenerative disorders. BioFactors (Oxford, England). 2010;36:370-6.

10. Bhandari R, Kuhad A. Resveratrol suppresses neuroinflammation in the experimental paradigm of autism spectrum disorders. Neurochem Int 2017; 103:8-23.

11. Gocmez SS, Gacar N, Utkan T, Gacar G, Scarpace PJ, Tumer N. Protective effects of resveratrol on aging-induced cognitive impairment in rats. Neurobiol Learn Mem. 2016;131:131-6.

12. Goldberg DM, Yan J, Soleas GJ. Absorption of three wine-related polyphenols in three different matrices by healthy subjects. Clin Biochem. 2003:36:79-87.

13. Sale S, Verschoyle RD, Boocock D, Jones DJ, Wilsher N, Ruparelia KC, et al. Pharmacokinetics in mice and growth-inhibitory properties of the putative cancer chemopreventive agent resveratrol and the synthetic analogue trans 3,4,5,4'-tetramethoxystilbene. Br J Cancer. 2004;90:736-44.

14. Uher R, Tansey KE, Dew T, Maier W, Mors O, Hauser J, et al. An inflammatory biomarker as a differential predictor of outcome of depression treatment with escitalopram and nortriptyline. Am J Psychiatry. 2014;171:1278-86.

15. Walle T. Bioavailability of resveratrol. Ann N Y Acad Sci. 2011;1215:9-15.

16. Wang $Q$, Xu J, Rottinghaus GE, Simonyi A, Lubahn D, Sun GY, et al. Resveratrol protects against global cerebral ischemic injury in gerbils. Brain Res. 2002:958:439-47.

17. Virgili M, Contestabile A. Partial neuroprotection of in vivo excitotoxic brain damage by chronic administration of the red wine antioxidant agent, trans-resveratrol in rats. Neurosci Lett. 2000;281:123-6.

18. Kennedy DO, Wightman EL, Reay JL, Lietz G, Okello EJ, Wilde A, et al. Effects of resveratrol on cerebral blood flow variables and cognitive performance in humans: a double-blind, placebo-controlled, crossover investigation. Am J Clin Nutr. 2010;91:1590-7.

19. Wong RH, Coates AM, Buckley JD, Howe PR. Evidence for circulatory benefits of resveratrol in humans. Ann NY Acad Sci. 2013;1290:52-8.

20. Dumont M, Beal MF. Neuroprotective strategies involving ROS in Alzheimer disease Free Radical Biol Med. 2011:51:1014-26.
21. Belguendouz L, Fremont L, Linard A. Resveratrol inhibits metal iondependent and independent peroxidation of porcine low-density lipoproteins. Biochem Pharmacol. 1997:53:1347-55.

22. de la Lastra CA, Villegas I. Resveratrol as an anti-inflammatory and anti-aging agent: mechanisms and clinical implications. Mol Nutr Food Res. 2005;49:405-30.

23. Bastianetto S, Zheng WH, Quirion R. Neuroprotective abilities of resveratrol and other red wine constituents against nitric oxiderelated toxicity in cultured hippocampal neurons. $\mathrm{Br} J$ Pharmacol. 2000;131:711-20.

24. Vella F, Ferry G, Delagrange $\mathrm{P}$, Boutin JA. NRH:quinone reductase 2: an enzyme of surprises and mysteries. Biochem Pharmacol. 2005;71:1-12.

25. Benoit CE, Bastianetto S, Brouillette J, Tse Y, Boutin JA, Delagrange P, et al. Loss of quinone reductase 2 function selectively facilitates learning behaviors. J Neurosci. 2010;30:12690-700.

26. Buryanovskyy L, Fu Y, Boyd M, Ma Y, Hsieh TC, Wu JM, et al. Crystal structure of quinone reductase 2 in complex with resveratrol. Biochemistry. 2004;43:11417-26.

27. Sakata Y, Zhuang H, Kwansa H, Koehler RC, Doré S. Resveratrol protects against experimental stroke: putative neuroprotective role of heme oxygenase 1. Exp Neurol. 2010;224:325-9.

28. Shibata R, Sato K, Pimentel DR, Takemura Y, Kihara S, Ohashi K, et al. Adiponectin protects against myocardial ischemia-reperfusion injury through AMPK- and COX-2-dependent mechanisms. Nat Med. 2005;11:1096-103.

29. Shin SM, Cho IJ, Kim SG. Resveratrol protects mitochondria against oxidative stress through AMP-activated protein kinase-mediated glycogen synthase kinase-3beta inhibition downstream of poly(ADP-ribose) polymerase-LKB1 pathway. Mol Pharmacol. 2009;76:884-95.

30. Perry VH, Nicoll JA, Holmes C. Microglia in neurodegenerative disease. Nat Rev Neurol. 2010;6:193-201.

31. Das S, Das DK. Anti-inflammatory responses of resveratrol. Inflamm Allergy Drug Targets. 2007;6:168-73.

32. Bi XL, Yang JY, Dong YX, Wang JM, Cui YH, Ikeshima T, et al. Resveratrol inhibits nitric oxide and TNF-alpha production by lipopolysaccharideactivated microglia. Int Immunopharmacol. 2005;5:185-93.

33. Candelario-Jalil E, de Oliveira AC, Gräf S, Bhatia HS, Hüll M, Muñoz E, et al. Resveratrol potently reduces prostaglandin E2 production and free radical formation in lipopolysaccharide-activated primary rat microglia. J Neuroinflamm. 2007;4:25.

34. Kim YA, Kim GY, Park KY, Choi YH. Resveratrol inhibits nitric oxide and prostaglandin E2 production by lipopolysaccharide-activated C6 microglia. J Med Food. 2007:10:218-24.

35. Kessler RC, Chiu WT, Demler O, Merikangas KR, Walters EE. Prevalence, severity, and comorbidity of 12-month DSM-IV disorders in the National Comorbidity Survey Replication. Arch Gen Psychiatry. 2005;62:617-27.

36. Nemeroff CB, Owens MJ. Treatment of mood disorders. Nat Neurosci. 2002:5(Suppl):1068-70.

37. Murrough JW, lacoviello B, Neumeister A, Charney DS, losifescu DV. Cognitive dysfunction in depression: neurocircuitry and new therapeutic strategies. Neurobiol Learn Mem. 2011;96:553-63.

38. Hasselbalch BJ, Knorr U, Hasselbalch SG. Cognitive deficits in the remitted state of unipolar depressive disorder. 2012;26:642-51.

39. Burmeister M. Basic concepts in the study of diseases with complex genetics. Biol Psychiat. 1999;45:522-32.

40. Manji HK, Drevets WC, Charney DS. The cellular neurobiology of depression. Nat Med. 2001;7:541-7.

41. Drzyzga $Ł R$, Marcinowska A, Obuchowicz E. Antiapoptotic and neurotrophic effects of antidepressants: a review of clinical and experimental studies. Brain Res Bull. 2009;79:248-57.

42. Videbech P. PET measurements of brain glucose metabolism and blood flow in major depressive disorder: a critical review. Acta Psychiatr Scand. 2000;101:11-20.

43. Karry R, Klein E, Ben Shachar D. Mitochondrial complex I subunits expression is altered in schizophrenia: a postmortem study. Biol Psychiat. 2004;55:676-84

44. Gardner A, Johansson A, Wibom R, Nennesmo I, von Döbeln U, Hagenfeldt $L$, et al. Alterations of mitochondrial function and correlations with personality traits in selected major depressive disorder patients. J Affect Disord. 2003;76:55-68. 
45. Hroudová J, Fišar Z, Kitzlerová E, Zvěřová M, Raboch J. Mitochondrial respiration in blood platelets of depressive patients. Mitochondrion. 2013:13:795-800

46. de Kloet ER, Joëls M, Holsboer F. Stress and the brain: from adaptation to disease. Nat Rev Neurosci. 2005;6:463-75.

47. Palta P, Samuel LJ, Miller ER 3rd, Szanton SL. Depression and oxidative stress: results from a meta-analysis of observational studies. Psychosom Med. 2014;76:12-9.

48. Camkurt MA, Fındıklı E, İzci F, Kurutaş EB, Tuman TC. Evaluation of malondialdehyde, superoxide dismutase and catalase activity and their diagnostic value in drug naïve, first episode, non-smoker major depression patients and healthy controls. Psychiatry Res. 2016:238:81-5.

49. Yager S, Forlenza MJ, Miller GE. Depression and oxidative damage to lipids. Psychoneuroendocrinology. 2010;35:1356-62.

50. Dimopoulos N, Piperi C, Psarra V, Lea RW, Kalofoutis A. Increased plasma levels of 8-iso-PGF2alpha and IL-6 in an elderly population with depression. Psychiatry Res. 2008;161:59-66.

51. Forlenza MJ, Miller GE. Increased serum levels of 8-hydroxy-2' deoxyguanosine in clinical depression. Psychosom Med. 2006:68:1-7.

52. Bajpai A, Verma AK, Srivastava M, Srivastava R. Oxidative stress and major depression. J Clin Diagn Res. 2014;8:4-7.

53. Maes M, De Vos N, Pioli R, Demedts P, Wauters A, Neels H, et al. Lower serum vitamin E concentrations in major depression. Another marker of lowered antioxidant defenses in that illness. J Affect Disord 2000;58:241-6.

54. Gautam M, Agrawal M, Gautam M, Sharma P, Gautam AS, Gautam S. Role of antioxidants in generalised anxiety disorder and depression. Indian J Psychiatry. 2012;54:244-7.

55. Maes M, Galecki P, Chang YS, Berk M. A review on the oxidative and nitrosative stress (O\&NS) pathways in major depression and their possible contribution to the (neuro)degenerative processes in that illness. Prog Neuropsychopharmacol Biol Psychiatry. 2011;35:676-92.

56. Raison CL, Capuron L, Miller AH. Cytokines sing the blues: inflammation and the pathogenesis of depression. Trends Immunol. 2006:27:24-31.

57. Miller AH, Maletic $V$, Raison CL. Inflammation and its discontents: the role of cytokines in the pathophysiology of major depression. Biol Psychiat. 2009;65:732-41.

58. Posar A, Resca F, Visconti P. Autism according to diagnostic and statistical manual of mental disorders 5(th) edition: the need for further improvements. J Pediatr Neurosci. 2015:10:146-8.

59. Miles JH. Autism spectrum disorders-a genetics review. Genet Med. 2011;13:278-94

60. Rossignol DA, Frye RE. Mitochondrial dysfunction in autism spectrum disorders: a systematic review and meta-analysis. Mol Psychiatry. 2012;17:290-314

61. James SJ, Melnyk S, Jernigan S, Cleves MA, Halsted CH, Wong DH, et al. Metabolic endophenotype and related genotypes are associated with oxidative stress in children with autism. Am J Med Genet B Neuropsychiatr Genetics 2006;141b:947-56.

62. Mostafa GA, El-Hadidi ES, Hewedi DH, Abdou MM. Oxidative stress in Egyptian children with autism: relation to autoimmunity. J Neuroimmunol. 2010;219:114-8.

63. Rossignol DA, Frye RE. Evidence linking oxidative stress, mitochondrial dysfunction, and inflammation in the brain of individuals with autism. Front Physiol. 2014;5:150.

64. Malaguarnera L. Influence of Resveratrol on the Immune Response. Nutrients. 2019;11.

65. Gomes BAQ, Silva JPB. Neuroprotective Mechanisms of Resveratrol in Alzheimer's Disease: Role of SIRT1. 2018;2018:8152373.

66. Vieth R. Vitamin D supplementation, 25-hydroxyvitamin D concentrations, and safety. Am J Clin Nutr. 1999;69:842-56.

67. Turner RS, Thomas RG, Craft S, van Dyck CH, Mintzer J, Reynolds BA, et al. A randomized, double-blind, placebo-controlled trial of resveratrol for Alzheimer disease. Neurology. 2015;85:1383-91.

68. Palmieri L, Persico AM. Mitochondrial dysfunction in autism spectrum disorders: cause or effect? Biochem Biophys Acta. 2010;1797:1130-7.

69. Rose S, Melnyk S, Pavliv O, Bai S, Nick TG, Frye RE, et al. Evidence of oxidative damage and inflammation associated with low glutathione redox status in the autism brain. Translational psychiatry. 2012;2:e134
70. Bhandari R, Paliwal JK, Kuhad A. Dietary phytochemicals as neurotherapeutics for autism spectrum disorder: plausible mechanism and evidence. Adv Neurobiol. 2020:24:615-46.

71. Saqib U, Kelley TT, Panguluri SK, Liu D, Savai R, Baig MS, et al. Polypharmacology or promiscuity? structural interactions of resveratrol with its bandwagon of targets. Front Pharmacol. 2018;9:1201.

72. Tandon R, Nasrallah HA, Keshavan MS. Schizophrenia, "just the facts" 4. Clinical features and conceptualization. Schizophrenia Res. 2009:110:1-23.

73. Rees $S$, Inder T. Fetal and neonatal origins of altered brain development. Early Human Dev. 2005;81:753-61.

74. Bale TL, Baram TZ, Brown AS, Goldstein JM, Insel TR, McCarthy MM, et al. Early life programming and neurodevelopmental disorders. Biol Psychiat. 2010;68:314-9.

75. Bilbo SD, Schwarz JM. Early-life programming of later-life brain and behavior: a critical role for the immune system. Front Behav Neurosci. 2009;3:14.

76. Burns TM, Clough JA, Klein RM, Wood GW, Berman NE. Developmenta regulation of cytokine expression in the mouse brain. Growth factors (Chur, Switzerland). 1993:9:253-8.

77. Potvin S, Stip E, Sepehry AA, Gendron A, Bah R, Kouassi E. Inflammatory cytokine alterations in schizophrenia: a systematic quantitative review. Biol Psychiat. 2008;63:801-8.

78. Maes M, Bocchio Chiavetto L, Bignotti S, Battisa Tura GJ, Pioli R, Boin F, et al. Increased serum interleukin-8 and interleukin-10 in schizophrenic patients resistant to treatment with neuroleptics and the stimulatory effects of clozapine on serum leukemia inhibitory factor receptor. Schizophr Res. 2002;54:281-91.

79. Bocchio Chiavetto L, Boin F, Zanardini R, Popoli M, Michelato A, Bignotti $\mathrm{S}$, et al. Association between promoter polymorphic haplotypes of interleukin-10 gene and schizophrenia. Biol Psychiat. 2002;51:480-4.

80. Xu M, He L. Convergent evidence shows a positive association of interleukin-1 gene complex locus with susceptibility to schizophrenia in the Caucasian population. Schizophr Res. 2010;120:131-42.

81. Rieder SA, Chauhan A, Singh U, Nagarkatti M, Nagarkatti P. Cannabinoid-induced apoptosis in immune cells as a pathway to immunosuppression. Immunobiology. 2010;215:598-605.

82. Brown AS. The environment and susceptibility to schizophrenia. Prog Neurobiol. 2011;93:23-58

83. Müller N, Krause D, Dehning S, Musil R, Schennach-Wolff R, Obermeier $M$, et al. Celecoxib treatment in an early stage of schizophrenia: results of a randomized, double-blind, placebo-controlled trial of celecoxib augmentation of amisulpride treatment. Schizophr Res. 2010;121:118-24.

84. Abd El-Fattah AA, Fahim AT, Sadik NAH, Ali BM. Resveratrol and dimethyl fumarate ameliorate depression-like behaviour in a rat model of chronic unpredictable mild stress. Brain Res. 2018;1701:227-36.

85. Liu T, Ma Y, Zhang R, Zhong H, Wang L, Zhao J, et al. Resveratrol ameliorates estrogen deficiency-induced depression- and anxiety-like behaviors and hippocampal inflammation in mice. Psychopharmacology. 2019;236:1385-99.

86. Fahim AT, Abd El-Fattah AA, Sadik NAH, Ali BM. Resveratrol and dimethy fumarate ameliorate testicular dysfunction caused by chronic unpredictable mild stress-induced depression in rats. Arch Biochem Biophys. 2019;665:152-65.

87. Shen JD, Zhang YW, Wang BY, Bai L, Lu SF, Zhu LL, et al. Effects of resveratrol on the levels of ATP, $5-\mathrm{HT}$ and GAP-43 in the hippocampus of mice exposed to chronic unpredictable mild stress. Neurosci Lett. 2020;735:135232

88. Chen WJ, Du JK, Hu X, Yu Q, Li DX, Wang CN, et al. Protective effects of resveratrol on mitochondrial function in the hippocampus improves inflammation-induced depressive-like behavior. Physiol Behav. 2017;182:54-61

89. Liu L, Zhang Q, Cai Y, Sun D, He X, Wang L, et al. Resveratrol counteracts lipopolysaccharide-induced depressive-like behaviors via enhanced hippocampal neurogenesis. Oncotarget. 2016;7:56045-59.

90. Gu Z, Chu L, Han Y. Therapeutic effect of resveratrol on mice with depression. Exp Ther Med. 2019;17:3061-4.

91. Cole AR. Glycogen synthase kinase 3 substrates in mood disorders and schizophrenia. FEBS J. 2013;280:5213-27. 
92. Ludka FK, Constantino LC, Dal-Cim T, Binder LB, Zomkowski A, Rodrigues AL, et al. Involvement of PI3K/Akt/GSK-3B and mTOR in the antidepressant-like effect of atorvastatin in mice. J Psychiatr Res. 2016;82:50-7

93. Silva R, Mesquita AR, Bessa J, Sousa JC, Sotiropoulos I, Leão P, et al. Lithium blocks stress-induced changes in depressive-like behavior and hippocampal cell fate: the role of glycogen-synthase-kinase-3beta. Neuroscience. 2008;152:656-69.

94. Ge L, Liu L, Liu H, Liu S, Xue H, Wang X, et al. Resveratrol abrogates lipopolysaccharide-induced depressive-like behavior, neuroinflammatory response, and CREB/BDNF signaling in mice. Eur J Pharmacol. 2015;768:49-57.

95. Voleti B, Duman RS. The roles of neurotrophic factor and Wnt signaling in depression. Clin Pharmacol Ther. 2012;91:333-8.

96. Jope RS, Roh MS. Glycogen synthase kinase-3 (GSK3) in psychiatric diseases and therapeutic interventions. Curr Drug Targets. 2006;7:1421-34.

97. Karege F, Perroud N, Burkhardt S, Schwald M, Ballmann E, La Harpe R, et al. Alteration in kinase activity but not in protein levels of protein kinase $B$ and glycogen synthase kinase-3beta in ventral prefrontal cortex of depressed suicide victims. Biol Psychiat. 2007:61:240-5.

98. Kaidanovich-Beilin O, Milman A, Weizman A, Pick CG, Eldar-Finkelman H. Rapid antidepressive-like activity of specific glycogen synthase kinase-3 inhibitor and its effect on beta-catenin in mouse hippocampus. Biol Psychiat. 2004;55:781-4.

99. Ge JF, Xu YY, Qin G, Cheng JQ, Chen FH. Resveratrol Ameliorates the Anxiety- and Depression-Like Behavior of Subclinical Hypothyroidism Rat: possible Involvement of the HPT Axis, HPA Axis, and Wnt/B-Catenin Pathway. Front Endocrinol. 2016;7:44.

100. Yang XH, Song SQ, Xu Y. Resveratrol ameliorates chronic unpredictable mild stress-induced depression-like behavior: involvement of the HPA axis, inflammatory markers, BDNF, and Wnt/B-catenin pathway in rats. Neuropsychiatr Dis Treatment. 2017;13:2727-36.

101. Shen J, Qu C, Xu L, Sun H, Zhang J. Resveratrol exerts a protective effect in chronic unpredictable mild stress-induced depressive-like behavior: involvement of the AKT/GSK3 3 signaling pathway in hippocampus. Psychopharmacology. 2019;236:591-602.

102. Wang F, Wang J, An J, Yuan G, Hao X, Zhang Y. Resveratrol ameliorates depressive disorder through the NETRIN1-mediated extracellular signalregulated kinase/cAMP signal transduction pathway. Mol Med Rep. 2018;17:4611-8.

103. Herman JP, Figueiredo H, Mueller NK, Ulrich-Lai Y, Ostrander MM, Choi DC, et al. Central mechanisms of stress integration: hierarchical circuitry controlling hypothalamo-pituitary-adrenocortical responsiveness. Front Neuroendocrinol. 2003;24:151-80.

104. McEwen BS, Stellar E. Stress and the individual. Mechanisms leading to disease. Arch Internal Med 1993;153:2093-101.

105. Akana SF, Dallman MF, Bradbury MJ, Scribner KA, Strack AM, Walker $C D$. Feedback and facilitation in the adrenocortical system: unmasking facilitation by partial inhibition of the glucocorticoid response to prior stress. Endocrinology. 1992;131:57-68.

106. Givalois L, Naert G, Rage F, Ixart G, Arancibia S, Tapia-Arancibia L. A single brain-derived neurotrophic factor injection modifies hypothalamo-pituitary-adrenocortical axis activity in adult male rats. Mol Cell Neurosci. 2004;27:280-95.

107. Naert G, Ixart G, Tapia-Arancibia L, Givalois L. Continuous icv infusion of brain-derived neurotrophic factor modifies hypothalamic-pituitaryadrenal axis activity, locomotor activity and body temperature rhythms in adult male rats. Neuroscience. 2006;139:779-89.

108. Li G, Wang G, Shi J, Xie X, Fei N, Chen L, et al. trans-Resveratrol ameliorates anxiety-like behaviors and fear memory deficits in a rat model of post-traumatic stress disorder. Neuropharmacology. 2018;133:181-8.

109. Yuan $Y$, Zhen L, Li Z, Xu W, Leng $H, X u W$, et al. trans-Resveratrol ameliorates anxiety-like behaviors and neuropathic pain in mouse model of post-traumatic stress disorder. 2020;34:726-36.

110. Maldonado-Bouchard S, Peters K, Woller SA, Madahian B, Faghihi U, Patel $\mathrm{S}$, et al. Inflammation is increased with anxiety- and depressionlike signs in a rat model of spinal cord injury. Brain Behav Immun. 2016:51:176-95.

111. Pan Y, Chen XY, Zhang QY, Kong LD. Microglial NLRP3 inflammasome activation mediates IL-1 $\beta$-related inflammation in prefrontal cortex of depressive rats. Brain Behav Immun. 2014:41:90-100.
112. Alzarea S, Rahman S. Effects of alpha-7 nicotinic allosteric modulator PNU 120596 on depressive-like behavior after lipopolysaccharide administration in mice. Prog Neuropsychopharmacol Biol Psychiatry. 2018;86:218-28.

113. Jiang Y, Langley B, Lubin FD, Renthal W, Wood MA, Yasui DH, et al. Epigenetics in the nervous system. J Neurosci. 2008;28:11753-9.

114. Urdinguio RG, Sanchez-Mut JV, Esteller M. Epigenetic mechanisms in neurological diseases: genes, syndromes, and therapies. Lancet Neurol. 2009:8:1056-72.

115. Bagul PK, Banerjee SK. Insulin resistance, oxidative stress and cardiovascular complications: role of sirtuins. Curr Pharm Des. 2013;19:5663-77.

116. Chakravarty S, Pathak SS, Maitra S, Khandelwal N, Chandra KB, Kumar A. Epigenetic regulatory mechanisms in stress-induced behavior. Int Rev Neurobiol. 2014:115:117-54

117. Bagul PK, Middela H, Matapally S, Padiya R, Bastia T, Madhusudana K, et al. Attenuation of insulin resistance, metabolic syndrome and hepatic oxidative stress by resveratrol in fructose-fed rats. Pharmacol Res. 2012:66:260-8

118. Reddy BR, Maitra S, Jhelum P, Kumar KP, Bagul PK, Kaur G, et al. Sirtuin 1 and 7 mediate resveratrol-induced recovery from hyper-anxiety in high-fructose-fed prediabetic rats. J Biosci. 2016;41:407-17.

119. Magaji MG, Iniaghe LO, Abolarin M, Abdullahi Ol, Magaji RA. Neurobehavioural evaluation of resveratrol in murine models of anxiety and schizophrenia. Metab Brain Dis. 2017;32:437-42.

120. Al Rahim M, Rimando AM, Silistreli K, El-Alfy AT. Anxiolytic action of pterostilbene: involvement of hippocampal ERK phosphorylation. Planta Med. 2013:79:723-30

121. Bambini-Junior V, Zanatta G, Della Flora Nunes G, Mueller de Melo G, Michels M, Fontes-Dutra M, et al. Resveratrol prevents social deficits in animal model of autism induced by valproic acid. Neurosci Lett. 2014:583:176-81.

122. Hendouei F, Sanjari Moghaddam H, Mohammadi MR, Taslimi N, Rezaei $\mathrm{F}$, Akhondzadeh S. Resveratrol as adjunctive therapy in treatment of irritability in children with autism: A double-blind and placebo-controlled randomized trial. 2020;45:324-34.

123. Hidema S, Kikuchi S, Takata R, Yanai T, Shimomura K, Horie K, et al. Single administration of resveratrol improves social behavior in adult mouse models of autism spectrum disorder. Bioscience, biotechnology, and biochemistry. 2020:1-8.

124. Xie W, Ge X, Li L, Yao A, Wang X, Li M, et al. Resveratrol ameliorates prenatal progestin exposure-induced autism-like behavior through ER $\beta$ activation. 2018:9:43.

125. Ashwood P, Krakowiak P, Hertz-Picciotto I, Hansen R, Pessah I, Van de Water J. Elevated plasma cytokines in autism spectrum disorders provide evidence of immune dysfunction and are associated with impaired behavioral outcome. Brain Behav Immun. 2011;25:40-5.

126. Enstrom AM, Lit L, Onore CE, Gregg JP, Hansen RL, Pessah IN, et al Altered gene expression and function of peripheral blood natural killer cells in children with autism. Brain Behav Immun. 2009:23:124-33.

127. Al-Ayadhi LY, Mostafa GA. Elevated serum levels of macrophagederived chemokine and thymus and activation-regulated chemokine in autistic children. J Neuroinflam. 2013;10:72.

128. Mishra BB, Mishra PK, Teale JM. Expression and distribution of Toll-like receptors in the brain during murine neurocysticercosis. J Neuroimmunol. 2006;181:46-56.

129. Ahmad SF, Ansari MA, Nadeem A, Alzahrani MZ, Bakheet SA, Attia SM. Resveratrol Improves Neuroimmune Dysregulation Through the Inhibition of Neuronal Toll-Like Receptors and COX-2 Signaling in BTBRT(+) Itpr3(tf)/J Mice. NeuroMol Med. 2018;20:133-46.

130. Bakheet SA, Alzahrani MZ, Ansari MA, Nadeem A, Zoheir KMA, Attia SM, et al. Resveratrol Ameliorates Dysregulation of Th1, Th2, Th17, and T Regulatory Cell-Related Transcription Factor Signaling in a BTBRT+tf/J Mouse Model of Autism. Mol Neurobiol. 2017;54:5201-12.

131. Fontes-Dutra M, Santos-Terra J, Deckmann I, Brum Schwingel G, Della-Flora Nunes G, Hirsch MM, et al. Resveratrol prevents cellular and behavioral sensory alterations in the animal model of autism induced by valproic acid. Front Synaptic Neurosci. 2018;10:9.

132. Ahmad SF, Ansari MA, Nadeem A, Bakheet SA, Alzahrani MZ, Alshammari MA, et al. Resveratrol attenuates pro-inflammatory cytokines and activation of JAK1-STAT3 in BTBR T(+) Itpr3(tf)/J autistic mice. Eur J Pharmacol. 2018;829:70-8. 
133. Bakheet SA, Alzahrani MZ, Nadeem A, Ansari MA, Zoheir KMA, Attia SM, et al. Resveratrol treatment attenuates chemokine receptor expression in the BTBRT $+\mathrm{tf} / \mathrm{J}$ mouse model of autism. Mol Cellular Neurosci. 2016;77:1-10.

134. Niu J, Cao Y, Ji Y. Resveratrol, a SIRT1 Activator, Ameliorates MK-801-Induced Cognitive and Motor Impairments in a Neonatal Rat Model of Schizophrenia. Front Psychiatry. 2020;11:716.

135. Busanello A, Leal CQ, Peroza LR, Röpke J, de Moraes Reis E, de Freitas $\mathrm{CM}$, et al. Resveratrol protects against vacuous chewing movements induced by chronic treatment with fluphenazine. Neurochem Res. 2017;42:3033-40.

136. Ferreira FR, de Moura NSB, Hassib L, Pombo TR. Resveratrol ameliorates the effect of maternal immune activation associated with schizophrenia in adulthood offspring. Neurosci Lett. 2020;734:135100.
137. Zortea K, Franco VC, Francesconi LP Cereser KM, Lobato ML, Belmontede-Abreu PS. Resveratrol supplementation in schizophrenia patients: a randomized clinical trial evaluating serum glucose and cardiovascular risk factors. Nutrients. 2016;8:73.

138. Zortea K, Franco VC, Guimarães P, Belmonte-de-Abreu PS. Resveratrol supplementation did not improve cognition in patients with schizophrenia: results from a randomized clinical trial. Front Psychiatry. 2016;7:159

\section{Publisher's Note}

Springer Nature remains neutral with regard to jurisdictional claims in published maps and institutional affiliations.
Ready to submit your research? Choose BMC and benefit from:

- fast, convenient online submission

- thorough peer review by experienced researchers in your field

- rapid publication on acceptance

- support for research data, including large and complex data types

- gold Open Access which fosters wider collaboration and increased citations

- maximum visibility for your research: over $100 \mathrm{M}$ website views per year

At BMC, research is always in progress.

Learn more biomedcentral.com/submissions 